\title{
Loa de la fraternidad y otros poemas
}

\author{
ORILLAS DEL GARONA
}

A Deme y Celina

Declina ya la tarde lentamente; nubes de oro por el cielo vagan;

los rebaños, ronceros, se rezagan; el prado nos acoge confidente.

Desnuda el agua, a nuestra vera canta su canción repetida y siempre nueva, que al alma, irresistible, hacia sí lleva, incapaz de sufrir belleza tanta.

Y enajenada, libre de cuidado, se hace fresno y zarzal sombrio y río $\mathrm{y}$ cielo $\mathrm{y}$ nube y pájaro y montaña,

fundida en un abrazo con la entraña del mundo, sin cansancio y sin hastio. ¡La tarde aquella, aquel recodo, el prado!

\section{CARMEN, ESCOLAR}

Os miro en los pupitres de la clase, indolentes, sin rumbo, a merced de la brisa del momento; $o$ en ahínco cavar en la poza honda del libro; o buscar afanosos, por los cauces oscuros, las palabras bruñidas, lustrales, recién hechas. 
Sois las olas,

que, en años sucesivos,

monótonas, sin pausa,

van llegando a la playa

y esculpen con su embate las orillas,

desbastando el cantil,

modelando su abrupta traceria,

abriendo amplia cenefa de arena acogedora que se hunde al

Mi destino es morir:

pisar.

desnacerme naciéndoos,

ser hontanar vivo

que brota y se derrama en canalillos bullidores

$\mathrm{y}$ se hunde en vuestra tierra

para aflorar en ella

en nuevo manantial claro, luminoso,

que buscará otros campos

y en ellos será vida y relumbre y frescor.

No hay camino.

Ni siquiera una trocha trazada de antemano.

Hay que abrirlo a golpe de tesón.

Trabajar sin desmayo,

avizor la mirada,

que, a veces, la verdad nos roza con su ala y pasa rauda, $y$, apenas, los despiertos le dan alcance al vuelo.

El saber no se impone desde fuera.

Es marea que sube desde dentro,

ansia que tantea calmar su desazón.

Como la savia, al llegar abril, estalla

y verdea la copa y la enflora de joyas,

que crecen hacia fruto,

y es querencia de pájaros en fiebre de trinos,

de suspiros, de amor;

así la ola interior

que fluye en vuestras venas:

onda divina, que incontenible se propaga;

voz, que seduce, que quema y que taladra;

amor, que se dilata y sube incontrastable;

libertad creadora,

que en la roca obstinada se crece y acrisola.

En la barranca agria,

desnudo erial de arcilla,

hunde el almendro su troncón retorcido, 
remejido de vientos, de lluvias y de soles;

mas sus ramas se alumbran con millares de ojos

perfumados.

Tal sea vuestra vida:

terquedad de transparencia,

sordo anhelar de altura,

concentrada floración sobre el abismo humano.

¡La raîz en las cárcavas, pero el ímpetu en Dios!

TRES SONETOS A SANTIBÁÑEZ DE TERA

$$
\text { 1.- El río }
$$

Con la primera luz de amanecida, cuando rezan el álamo y la rosa, el alma se recoge silenciosa y te adora, "Verdad, Camino y Vida".

Y se queda de hinojos, sorprendida y en olvido -cual sauce que reposa su dolor sobre el agua soledosa-, concentrada en plegaria enardecida.

¡Ay, orillas del Tera, soñadero de mi dulce y siempre vivo tormento, a vuestros flancos siempre prisionero!

¡La voz del agua, las guijas, el viento en los chopos! Mi corazón viajero os recuerda desde el viejo convento.

\section{2.- Viñas y rastrojos}

Está el campo seco; arde la mañana y es la campiña un candelabro de oro. Tal es el sol que quema la besana, esta besana que yo quiero y adoro!

El valle se solivia en los cabezos -jayanes con viñedos por monteray el verde de la vid en la ladera repara del rastrojo los acezos. 
Es la brisa cual gigantesco pomo de uvas en flor y mostos presentidos en esta hora ardorosa y veraniega.

$\mathrm{Y}$ el zureo inefable del palomo y el rumor de los chopos verdecidos brizan del campo la matriz paniega.

\section{3.- Las encinas}

iLa paz sedeña de los encinares de mi tierra! ¡La loma empenachada de estrellas, sin ventalle, recatada con silencios de quietos colmenares!

De su hombrera, encinas por alamares van cayendo hasta dar en la hondonada. Huele la noche a mies recién cortada, $\mathrm{y}$ andan fantasmas por los calvijares.

Antes que el hacha airada os convierta en tronco informe o rompedor arado, que abra la entraña de la tierra muerta, permitid que un soneto afervorado os dedique, encinares patriarcales, que habéjs visto el crecer de los trigales.

\section{LOA DE LA COMUNIDAD PARROQUIAL}

Ramo de Santibáñez de Tera en honor

de san Tirso

\section{1.- Nuestra herencia}

Coro

Alegres aquí venimos para cantar en tu fiesta a ti, san Tirso bendito, hoy, que acaba la novena.

Voz de innumerables aguas en nuestro canto resuena: es la voz de nuestros padres, que nos dieron esta herencia. 
Como un dia te cantaron ellos, hoy las voces nuestras escucha; y que nuestros hijos continúen esta senda.

Con el símbolo cristiano del pan y el vino, presencia de Cristo, darte homenaje queremos: él fue tu fuerza.

Pueblo

Darte homenaje queremos en Cristo, que él fue tu fuerza; arraigarnos en su vida $y$ ser aquí su presencia.

\section{2.- Nuestra tierra}

Coro

Ya los panes van crecidos y arde mayo en la arboleda; las viñas están en ciernes y las palomas zurean.

Cielo azul y "luz no usada" bañan de gozo la tierra y es una hermosura el valle, monte, viñas, tesos, vega.

El rio pasa cantando y vaga la primavera encendiendo farolillos de flores por la ribera.

Tiembla la vida naciente, balan de amor las ovejas y en los alambres chirrian golondrinas blanquinegras.

Cual pujante árbol surgido de la entraña de esta tierra, nuestra vida se hace canto $\mathrm{y}$ a Cristo por ti hoy celebra.

Nuestra vida se hace canto y a Cristo por ti hoy celebra, cual pujante árbol surgido de la entraña de esta tierra. 
3.- Nuestra comunidad

Coro

Nuestras vidas, hermanadas, crecen, se amplian, aumentan, al mirar con rostro amigo al que pasa a nuestra vera.

$\mathrm{Y}$ menguan y se empobrecen, cuando cerramos la puerta a aquel que nos necesita $\mathrm{y}$ en soledad vive y pena.

Somos fronda de un mismo árbol: con el aire y las estrellas, con las plantas y animales, con el hombre en convivencia.

Sutil red entretejida de ocultos hilos de seda, mutuamente nos hacemos en la diaria tarea.

Y Dios está con nosotros, dando vida a la faena $\mathrm{y}$ haciéndonos hijos suyos, siempre que estamos "en vela".

"En vela", pues: confirmemos del bautismo las promesas, bien provistas nuestras lámparas con aceite de obras buenas.

Pueblo Nuestras lámparas provistas con aceite de obras buenas tenemos y confirmamos del bautismo las promesas

\section{4.- Nuestra oración}

Coro

En este dia de gracia, nuestras plegarias se adensan y suben hacia ti, Padre, derechas como saetas.

Que, en todo el mundo, tu nombre de Padre aclamado sea $\mathrm{y}$ tu designio cumpliendo los hombres por rey te tengan.

Por los que rigen los pueblos, por nuestro rey y la reina, 
por nuestro alcalde: la paz, y la justicia promuevan.

Porque al mandato de Cristo

fiel se mantenga la Iglesia y enseñe a todos los hombres a vivir la Buena Nueva.

Por el papa y los obispos nuestro corazón te reza y por los curas presentes: dales, Dios, tu gracia plena.

Y por los laicos que vida y tiempo dan a la Iglesia; por todos los catequistas, que a la Palabra se entregan.

Por todos nuestros difuntos, que vivieron con fe recia. $Y$ por los niños: que vivan con la misma fortaleza.

Por nosotros, que hoy cantamos a san Tirso en esta fiesta: vivamos fieles a Cristo, sea el amor nuestro lema.

Pueblo

Fieles vivimos a Cristo; el amor es nuestro lema. Por él, Dios, nuestras plegarias acoge $y$ dales respuesta.

\section{5.- Nuestra Eucaristía}

Cuanto somos y tenemos

Coro aquí está: es nuestra ofrenda, junto con el pan y el vino.

Hazlos vida y transparencia.

"Este es mi cuerpo", dijiste, que por vosotros se entrega, y mi sangre derramada por la muerte violenta.

$\mathrm{Y}$ así os seré pan de vida, dado en alianza eterna.

"Hacedlo en memoria mía hasta el dia en que yo vuelva". 
En tu memoria, Señor, acudimos a tu mesa.

Somos pueblo que en ti cree $y$ a ti te ama y en ti espera.

Danos ser una familia distinguida por tus señas, que al vecino y al extraño sirva con piedad fraterna.

Trabajaremos unidos por hacer de nuestra aldea un pueblo limpio y tranquilo, flor de virtudes y letras.

Suene el tambor y la gaita, cante el martillo y la rueda, que Dios está donde un hombre sueña, trabaja, ama y crea.

Tú, madre nuestra, Maria, oyente de Dios, maestra de cristianos, haz que todo esto realidad nos sea.

Pueblo

Oyente de Dios, María, y de cristianos maestra, haz que nuestras peticiones viva realidad nos sean.

\section{6.- Nuestro compromiso}

Coro

Celebremos, pues, alegres y hermanados, nuestra fiesta y vivamos siempre unidos en' casa, campo y plazuelas.

Siempre unidos, siempre amigos (que la unión hace la fuerza y crea y moldea al hombre), seamos viviente Iglesia.

Pueblo Con júbilo celebramos, hermanados, nuestra fiesta, Siempre unidos, siempre amigos, seremos viviente Iglesia (bis) 


\section{¡ADENTRO!}

iAdentro, al meollo, adentro!

Como la fuente que,

invadida

del prado al que da vida

y del árbol sensitivo que a su vera

prospera

(y el favor le devuelve con su sombra)

y de la brisa que frunce sus espejos

y del azul del cielo que en su fondo se mira,

se fijara,

concentrada,

en si misma

$\mathrm{y}$, entornando sus ojos bullidores, siguiera su vena hasta la roca donde tiene inagotable,

eterno,

su venero.

Como la rosa que,

inundada

de su perfume de éxtasis

y de la gloria del jardín radiante

y de la luz que es sólo luz

y del gozo de la nube con sol en el poniente,

se adentrara en sí misma

$\mathrm{y}$, siguiendo su savia, llegara a sus

raices

y sintiera la tierra que es su vida y la nutre.

Así voy yo,

penetrado de luz y frondas musicales

y aroma de campo

y agua clara

y cielo azul,

por el oscuro cauce de mi vida

hasta dar en Tu hontana sin suelo y sin orillas

y en Tu tierra viviente, que a todos nos sustenta.

Que el dentro más adentro

es el fuera más afuera y más excelso. 


\section{¿AFUERA!}

¡Morabitos, dejad vuestros cenobios, vuestra siesta segura, el Gran Silenciol ${ }^{1}$

A la calle, al taller, al campo, al aula, al hostigo del cierzo:

la tierra es nuestra herencia y sacramento el cuerpo.

$\mathrm{El}$ interior no existe: en trato con el mundo se va haciendo y cuesta Dios y ayuda de pequeñas verdades el encuentro. No hay dentro, si fuera no arrojamos el arpón primero. Cuidad que no se pueble de fantasmas, de las tinieblas hijos y del sueño.

Bajad ya de la luna; caminad con pie llano por el suelo; trabajad y morid por esta tierra; sembrad a todo viento.

Romped las alambradas que rodean, aislantes, vuestros guetos. Alumbre vuestros claustros el claro sol del claro pensamiento que hable del hombre de hoy y llegue hasta su centro.

A la vida, a vivir en la gran rosa de la vida, dentro! $Y$ trascienda desde ella, irresistible, su perfume de nardo el evangelio.

1. Silencio mayor se llamaba en los conventos el silencio después de la comida, la siesta. 


\section{FÁBULA CON CODA}

Encerrada Leonora, con muñecas distraía sus ocios malviviendo.

Altas tapias la aislaban de la vida; doncellas y animales hembras dentro de la casa, no más.

Vigilante, el celoso extremeño escalonó cerrojos a la entrada, no fuera alguien a despertarle el sexo.

Ella, ingenua, tomó por libertad $\mathrm{y}$ vida la maquinación del viejo.

Celoso de sus celos, un buen día quiso hacer experimento y saber si su esposa le era casta. A la astucia de Loaysa y su veneno se rindió Leonora.

Moraleja del cuento:

Madre, la mi madre, guardas me ponéis; que si yo no me guardo, no me guardaréis.

Así en los seminarios de posguerra, que llamaban de Trento, levantaron torreones y murallas que aislaran de la vida, del mal viento del mundo, de los hombres, leña para el infierno.

Fuera, el pecado, el mal, el aquelarre; dentro, la luz, el espíritu sin cuerpo.

Aún con el fervor de la cruzada, una España de Dios era su sueño.

Un buen dia, cayeron las murallas y el río de la vida irrumpió fiero, llevándose, implacable, nacientes flores y talludos maestros.

Virtud es libertad;

virtud es lucidez, conocimiento, 
Nunca más olvidemos esta historia; aprendamos el cuento.

Coda: $\quad$ Virtud es libertad.

Mas la burra del guarda -esto es ciertono pasa de ser burra, bien que libre.

Virtud es lucidez, conocimiento.

La libertad exige para hacerse

disciplina y rigor: el aire opuesto sostén y empuje le es a la paloma.

La lucidez no es don que envie el cielo:

se hace, se va haciendo en la ardua brega

que excita las sinapsis del cerebro.

La inspiración no existe;

no creas en agüeros.

Hay genes, hay herencia

$\mathrm{y}$, aún más, transpiración, afán, esfuerzo.

\section{AUNQUE ES DE NOCHE}

"Que bien sé yo la fuente que mana y corre, aunque es de noche"

(San Juan de la Cruz)

Es de noche.

Estamos al raso y la helada arrecia.

Mas yo sé dónde la hoguera

de vida, que alumbra y calienta:

"recibid el Espiritu; marchad a las nacionès".

Es de noche.

Agobia el cansancio y la sed aprieta.

Mas yo sé dónde la fuente

de vida, que calma y aguija:

"recibid el Espiritu; amaos unos a otros".

Es de noche.

Se enrarece el aire y el calor asfixia.

Mas yo sé dónde la brisa

de vida, que alivia y esfuerza:

"recibid el Espíritu; marchad a Galilea".

Es de noche.

Nos falla la tierra y el vértigo angustia. 
Mas yo sé dónde la roca

de vida, que sustenta e impulsa:

"recibid el Espíritu; haceos servidores".

Roca, brisa, fuente, hoguera

para el frio y la sed, el calor y la angustia.

\section{"LA DOLOROSA" DE PEDRO DE MENA}

\section{Realizada en diversas tallas}

Perdida en lontananza la mirada o entornada hacia dentro. ;Todo vano! Velado del dolor tu rostro humano. Inerme. Sin arrimo. ¡Desolada!

Huérfana de Jesús. Anonadada. Sacudida del odio ruin, aldeano. Los hombres en huida. Dios lejano. A solas con tu llanto. ¡Desolada!

$\mathrm{Ni}$ una brisa tu manto azul, tu velo acaricia. Indiferente el cielo. Ajena a tu dolor, la vida. ISola!

Abandonada en Dios y en Dios creyendo. De Dios abandonada, lay!, viviendo tu pura desnudez humana. ¡Sola! ${ }^{2}$.

José VEGA

2. "La soledad es siempre soledad de alguien, es decir, es un quedarse solo y un echar de menos [...] Nuestra Señora de la Soledad es la Virgen que se queda sola de Jesús, que lo han matado" (Ortega y Gasset, El hombre y la gente (=Colec. Austral 1501), Edit. Espasa-Calpe, Madrid 1972, 46-47). La vida es "lo que somos en radical soledad [...], en la pavorosa desnudez de sí mismo ante sí mismo [...] Dios es el que es presente precisamente como ausente; es el inmenso ausente que en todo presente brilla por su ausencia [...] Dejarnos solos con la realidad de las cosas, de modo que entre éstas y nosotros no hay nada ni nadie que las vele, cubra, finja ni oculte, y el no haber nada entre ellas y nosotros, eso es la verdad. El maestro Eckehart -el más genial de los místicos europeosllama por eso a Dios "el silente desierto que es Dios" (Id.: ib., 86-88). 